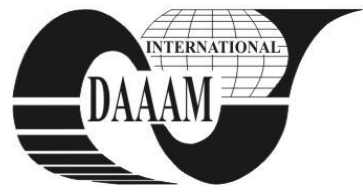

\title{
FINITE ELEMENT EVALUATION OF CAST METAL CROWNS MARGIN GEOMETRY
}

\author{
SANDU, L[iliana]; TOPALA, F[lorin] I[onel] \& POROJAN, S[orin]
}

\begin{abstract}
The objective of this study was to evaluate, by finite element analysis (FEA), the influence of different margin designs on the stress distribution in teeth prepared for cast metal crowns. Three margin designs were taken into consideration: shoulder, chamfer, and shoulderless. For each kind of preparation three dimensional finite element analyses were initiated. Maximal equivalent stresses were calculated and stress patterns were represented in order to compare the marginal designs. Maximal stress values were similar for all preparation types and in all cases they were recorded under the preparation line. Within the limitation of this study, the chamfer margin preparations of the teeth are preferred for cast metal crowns from biomechanical point of view.

Key words: finite element analysis, cast metal crown, margin geometry, stresses, prepared teeth
\end{abstract}

\section{INTRODUCTION}

The incomplete fit of full cast crown restorations remains a critical problem for dentists, leading many researchers to study this problem (Olivera \& Saito, 2006).

Marginal and internal accuracy of fit is valued as one of the most important criteria for the clinical quality and success of complete crowns (Bindl \& Mormann, 2005).

The geometry of tooth preparation has been the subject of many debates without clear evidence that one type of tooth preparation or method of fabrication provides consistently superior marginal fit (Ayad, 2009).

Traditional tooth preparation margin designs are still advised by most manufacturers for indirect restorations (Tsitrou $\&$ van Noort, 2008). Mainly five margin designs are used: shoulderless, chamfer, shoulder, sloped shoulder and shoulder with bevel.

Although they are conservative for tooth structure, shoulderless crown preparations should be avoided because they fail to provide adequate bulk at the margins. Overcontoured restorations often result from shoulderless preparations. Under most circumstances, these kinds of margins are unacceptable.

A chamfer margin is particularly suitable for cast metal crowns. It is distinct and easily identified, provides space for adequate bulk of material, although care is needed to avoid leaving a ledge of unsupported enamel.

Shoulder margins always offer space for the crown material. It should form a 90 degree angle with the unprepared tooth surface.

It was also found that margin design is a determining factor in establishing the extent of the minimal preparation for a cast metal crown (Tsitrou \& van Noort, 2008).

The shoulder preparation emerged as the recommended preparation design from both mechanical and periodontal points of view. As for a less invasive preparation design, the slight chamfer preparation would be the recommended option (Beuer et al., 2008).

Beside the described advantages and disadvantages of different margin designs for complete crown preparations, they influence the stress distribution in the prepared teeth. Loadbearing capacity is a further a crucial factor influencing the clinical long-term reliability of crowns (Kohorst et al., 2009).

Knowledge of factors, which influence stress and its distribution, is of key importance to the successful production of durable restorations (De Jager et al., 2005).

\section{AIM}

The objective of this study was to evaluate, by finite element analysis (FEA), the influence of different margin designs on the stress distribution in teeth prepared for cast metal crowns.

\section{MATERIALS AND METHOD}

To evaluate the influence margin design on stresses in the prepared teeth for complete cast crowns, a pilot study was achieved. Experimental models were created to simulate the simplified geometry of the prepared crowns.

Three margin designs were taken into consideration: shoulderless, chamfer, and shoulder. These preparations were covered with simplified crowns to simulate la physiologic loading conditions. A load of $5 \mathrm{~N}$ was applied on the occlusal surface of the simplified crown.

\section{RESULTS AND DISCUSSIONS}

This study was a preliminary evaluation of three margin preparation designs proposed for cast metal crowns. The values of the maximal equivalent stress were higher for the shoulder (Fig. 1). Regarding the distribution the maximal values, they are located under the preparation line.

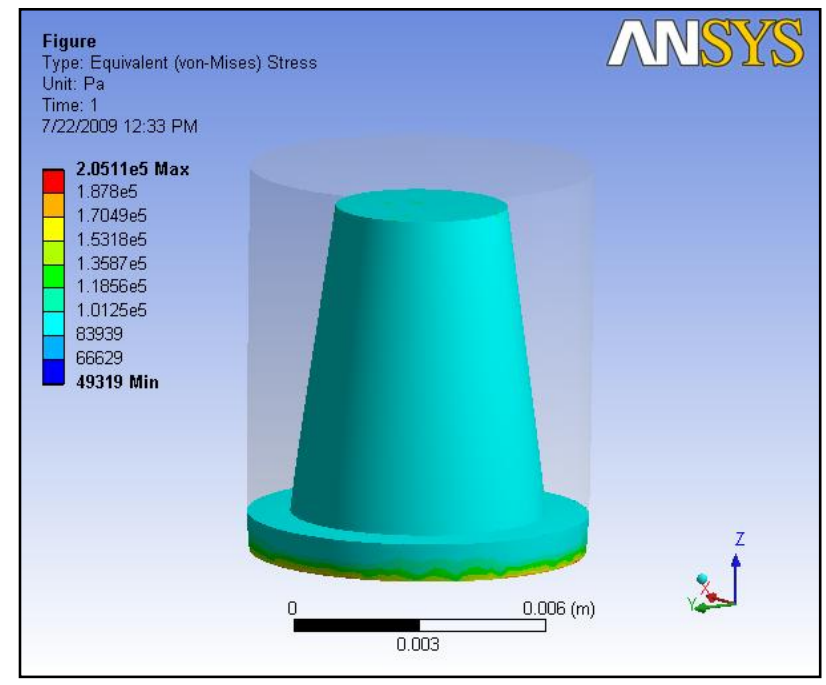

Fig. 1. Maximal equivalent stress in a tooth preparation with shoulder margin (fine simulation) 
For the other type of margin designs: chamfer, and shoulderless, the values of the maximal stresses were smaller (Tab. 1). They were located also under the preparation line (Fig. 2, 3). This is a favorable aspect because the stresses are not in the luting agent areas. This avoids being an additional factor for cement washout.

Chamfer preparations are the most favorable from this point of view. The stress patterns that lead to stresses at the junction of the teeth with the restorations are smaller.

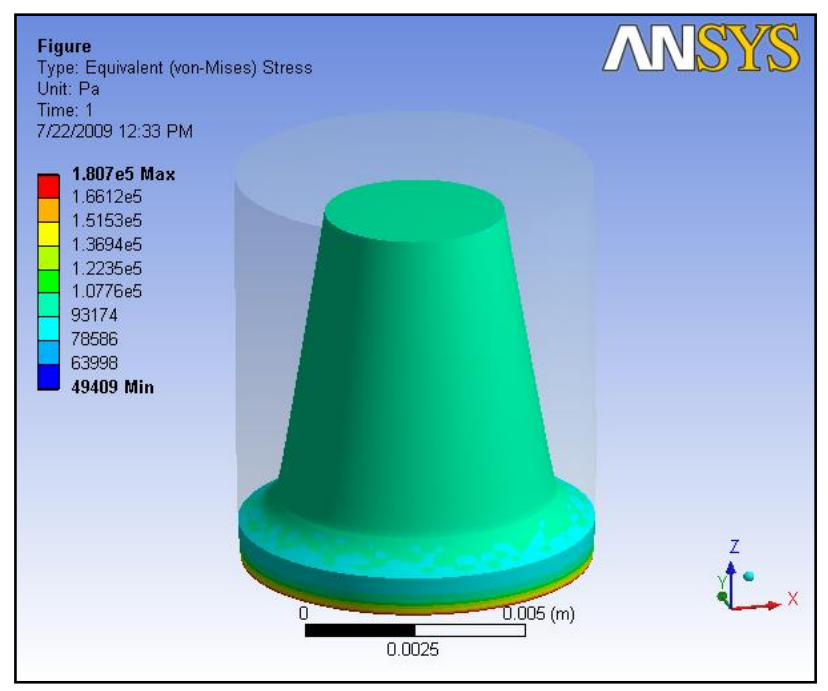

Fig. 2. Maximal equivalent stress in a tooth preparation with chamfer margin (fine simulation)



Fig. 3. Maximal equivalent stress in a tooth preparation with shoulderless margin (fine simulation)

\begin{tabular}{|l|l|}
\hline Preparation type & $\begin{array}{l}\text { Maximal equivalent stress } \\
{[\mathrm{Pa}]}\end{array}$ \\
\hline Shoulder margin & $2.0511 \mathrm{e}+5$ \\
\hline Chamfer margin & $1.8070 \mathrm{e}+5$ \\
\hline Shoulderless margin & $1.9173 \mathrm{e}+5$ \\
\hline
\end{tabular}

Tab. 1. Maximal equivalent stress in the tooth preparation

Regarding the stress distribution, the largest area is present for the shoulder preparation, followed by the shoulderless preparation. The stresses present in the preparation areas are an additional unfavorable factor for cracks in the luting agent.

The structural integrity and design of the teeth structures is an important problem in prosthodontics.

A possible reason for the most favorable stress distribution associated with chamfer margin preparations this could be that the occlusal forces were also borne by the circumferential preparation, and there was less stress concentration on the axial walls compared to other preparation designs.

The favorable results of the stress distribution at shoulderless preparation might be explained by the stress distribution pattern during loading. When load on the crown was increased, the crown could slide down the axial wall of the die without being limited by the margin.

The chamfer preparations did not differ significantly with regard to breaking load. This could be attributed to the adequate strength attained with preparation designs that require minimal removal of sound tooth structure. In light of this result, consideration should be given to these designs from a prophylactic point of view with emphasis on conserving tooth structure and preventing preparation trauma (De Jager et al., 2005).

Maximal stress values were similar for all preparation types and in all cases they were recorded under the preparation line. From this point of view they didn't affect the stresses in the prepared areas of the die.

\section{CONCLUSION}

Within the limitations of the present study, the chamfer preparation emerged as the recommended preparation design from biomechanical point of view.

Regarding stress distribution, it is followed by the shoulderless preparation. Shoulder is less favorable only from stress distribution point of view.

Maximal stress values were similar for all preparation types and in all cases they were recorded under the preparation line. This is a favorable aspect because the stresses are not in the luting agent areas and avoids being an additional factor for cement washout. Further research could correlate these results with other points of view regarding the preparation design.

\section{ACKNOWLEDGEMENTS}

This work was supported by CNCSIS-UEFISCSU, project number PN II-RU TE_217/2010.

\section{REFERENCES}

Ayad, M. F. (2009). Effects of Tooth Preparation Burs and Luting Cement Types on the Marginal Fit of Extracoronal Restorations. J Prosthodont, 18:145-51, ISSN 0893-2174

Beuer, F.; Aggstaller, H.; Edelhoff, D. \& Gernet, W. (2008). Effect of Preparation Design on the Fracture Resistance of Zirconia Crown Copings. Dent Mater, 27(3): 362-7, ISSN 0109-5641

Bindl, A. \& Mormann W.H. (2005). Marginal and internal fit of all-ceramic $\mathrm{CAD} / \mathrm{CAM}$ crown-copings on chamfer preparations. J Oral Rehabil, 32(6):441-7, ISSN 0305$182 \mathrm{X}$

De Jager, N.; Pallav, P. \& Feilzer, A.J. (2005). The influence of design parameters on the FEA-determined stress distribution in CAD-CAM produced all-ceramic dental crowns. Dent Mater, 21(3):242-51, ISSN 0109-5641

Kohorst, P.; Brinkmann, H.; Li J.; Borchers, L. \& Stiesch, M. (2009). Marginal accuracy of four-unit zirconia fixed dental prostheses fabricated using different computer-aided design/computer-aided manufacturing systems, Eur J Oral Sci, 117(3):319-25, ISSN 0909-8836

Olivera, A.B. \& Saito, T. (2006). The Effect of Die Spacer on Retention and Fitting of Complete Cast Crowns. $J$ Prosthodont, 15:243-9, ISSN 0893-2174

Tsitrou, E.A. \& van Noort, R. (2008). Minimal preparation designs for single posterior indirect prostheses with the use of the Cerec system. Int J Comput Dent, 11(3-4):227-40, ISSN 1463-4201 